\title{
Loop observe and snare technique for endoscopic resection of a gastric inflammatory fibroid polyp
}

A 51-year-old woman with epigastric pain and weight loss underwent upper gastrointestinal endoscopy following admission to our hospital. The endoscopy revealed a large polypoid mass with a thick stalk at the gastric antrum. Endoscopic ultrasound showed a 3-cm, hypoechoic, homogeneous lesion with indistinct margins originating from the submucosal layer, without involvement of the muscularis propria ( Fig. 1). We carried out endoloop (Olympus Optical Company, Tokyo, Japan) ligation and the loop was tightened around the stalk ( Fig.2). After 72 hours, a submucosal injection was given and snare excision carried out successfully ( Fig.3). The mucosal defect was closed with three hemoclips. Pathologic examination revealed spindle cells arranged in a concentric, onion skin-like formation in the submucosal layer, accompanied by inflammatory cell infiltration ( Fig.4). These findings were consistent with the diagnosis of an inflammatory fibroid polyp (IFP). The patient recovered uneventfully.

IFP is a rare mesenchymal lesion of the gastrointestinal tract. It has been regarded as a reactive polyp, but recent studies have indicated malignant potential [1]. Surgical resection is the generally accepted treatment modality in these cases because of the relatively large tumor size and difficulty in endoscopic resection using standard electrosurgical techniques [2]. There are few reports of endoscopic snare resection of gastric submucosal lesions. The "ligate and let go" method, after endoloop insertion, allows the lesion to slough spontaneously [3]. The limitation of this technique is the difficulty in specimen retrieval; therefore it may not be a suitable option for solitary submucosal lesions in which the pathologic evaluation indicates a need for surgical intervention. In another study, ligation and resection were carried out in the same session [4]. In our method, the interval between liga-

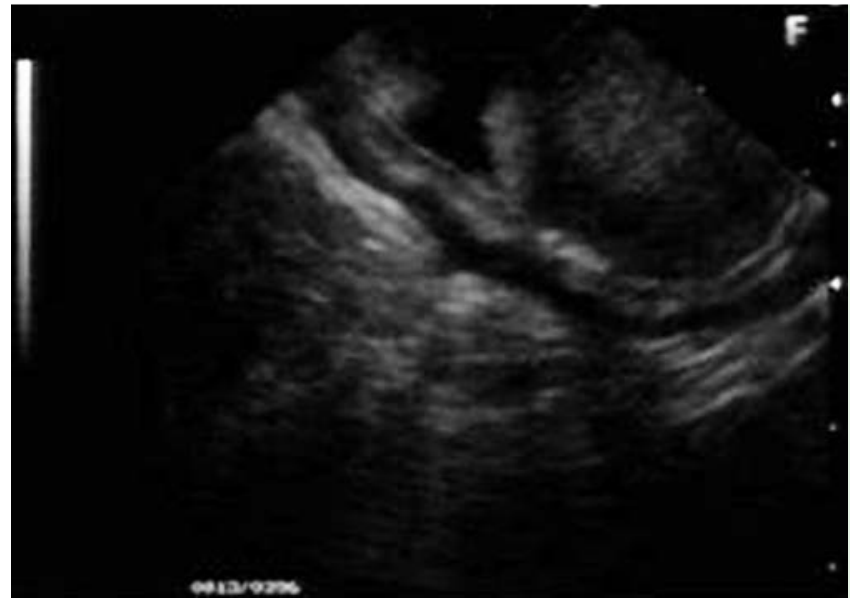

Fig. 1 Endoscopic ultrasound in a 51-yearold woman with epigastric pain and weight loss showing a hypoechoic, homogeneous lesion with indistinct margins originating from the submucosal layer. The muscularis propria layer was intact and not involved.

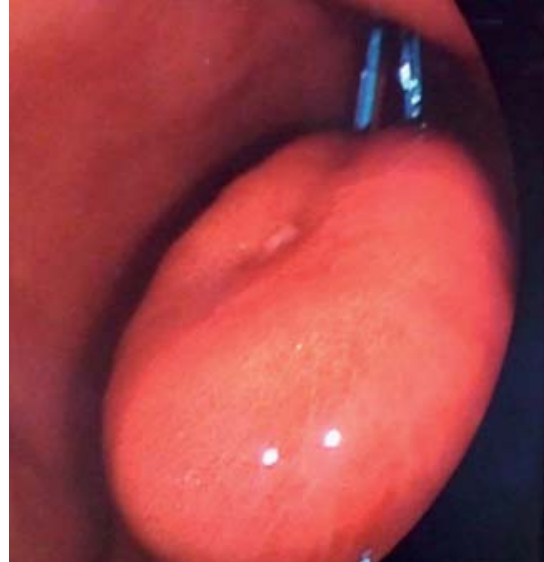

Fig.2 Endoloop ligation with the loop tightened around the stalk of the polypoid lesion.

tion and resection allows the blood supply to deteriorate, causing ischemia and subsequent reduction in the size of the stalk and facilitating resection of the lesion.

\section{Endoscopy_UCTN_Code_TTT_1AO_2AG}

Competing interests: None

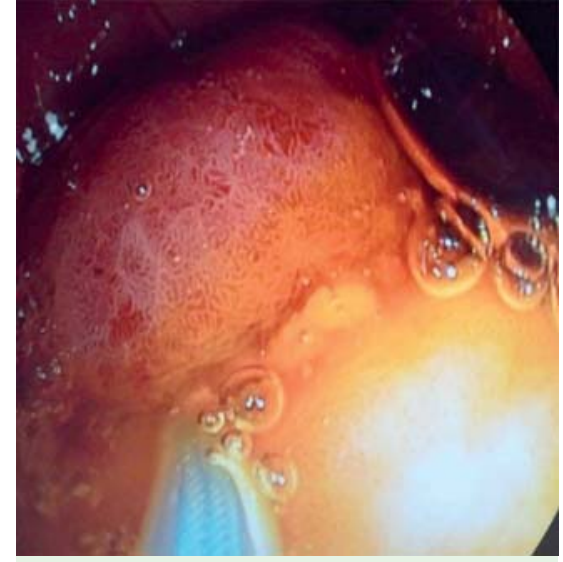

Fig. 3 Snare excision of the polyp.

\section{Ergun ${ }^{1}$, N. Zengin², E. Kayacetin ${ }^{1}$}

${ }^{1}$ Department of Gastroenterology, Turkiye Yuksek Ihtisas Education and Training Hospital, Ankara, Turkey

${ }^{2}$ Department of Pathology, Turkiye Yuksek Ihtisas Education and Training Hospital, Ankara, Turkey 

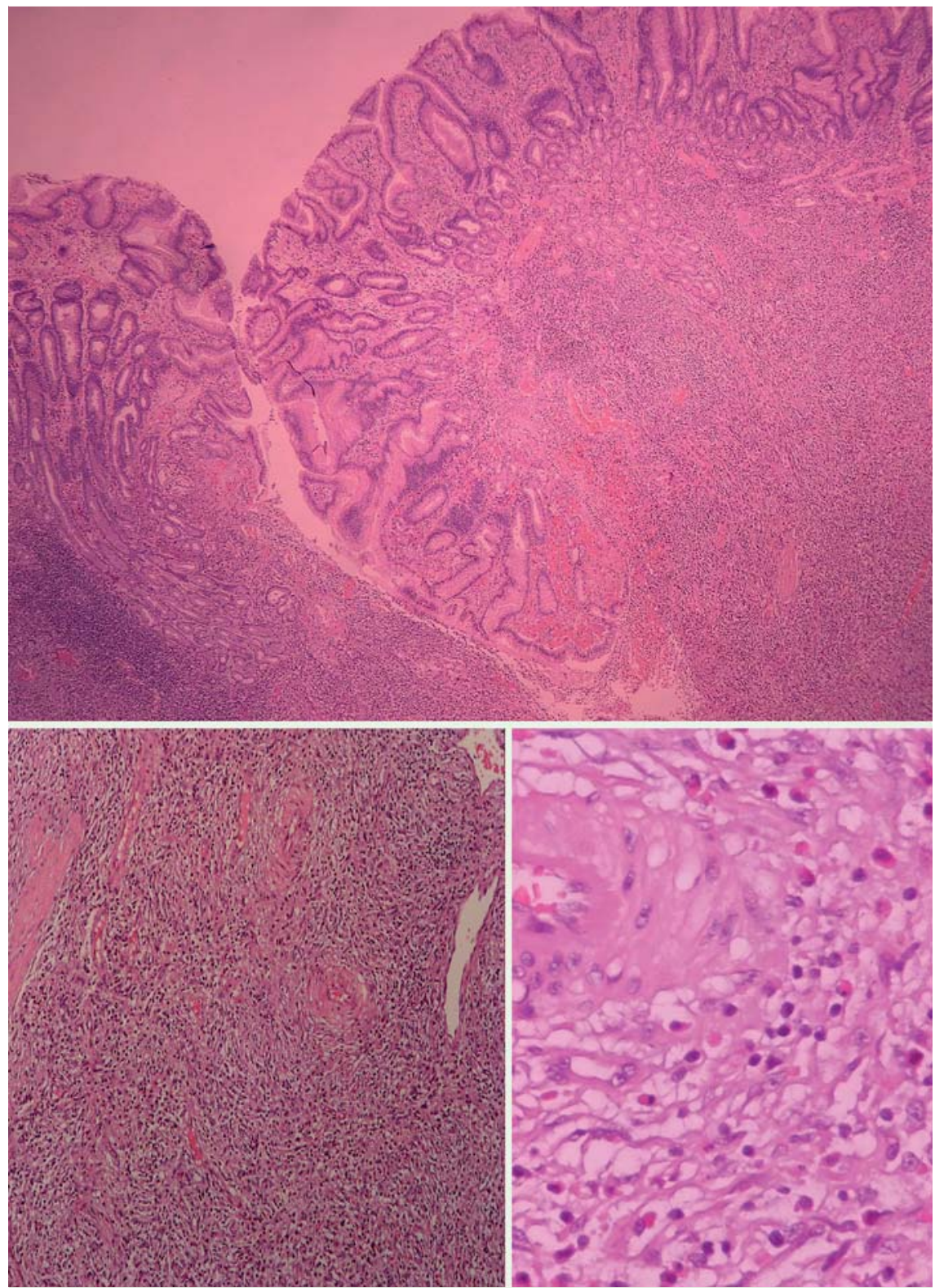

Fig. 4 Histologic section showing the spindle cells arranged in an onion skin-like concentric formation in the submucosal layer. There is accompanying inflammatory cell infiltration, predominantly eosinophils, fibroblasts, and histiocytes, and capillary proliferation.

\section{References}

1 Yamashita K, Arimura Y, Tanuma T et al. Pattern of growth of a gastric inflammatory fibroid polyp with PDGFRA overexpression. Endoscopy 2011; 43 (Suppl. 2): E171 - 172

2 Wolfsohn DM, Savides TJ, Easter DW et al. Laparoscopy-assisted endoscopic removal of a stromal-cell tumor of the stomach. Endoscopy 1997; 29: 679-682

3 Lee SH, Park JH, Park do H et al. Endoloop ligation of large pedunculated submucosal tumors. Gastrointest Endosc 2008; 67 (3): $556-560$

4 Huang WH, Feng CL, Lai HC et al. Endoscopic ligation and resection for the treatment of small EUS-suspected gastric GI stromal tumors. Gastrointest Endosc 2010; 71 (6): $1076-1081$

\section{Bibliography}

DOI http://dx.doi.org/

10.1055/s-0031-1291640

Endoscopy 2012; 44: E86-E87

(c) Georg Thieme Verlag KG

Stuttgart · New York

ISSN 0013-726X

\section{Corresponding author}

\section{Ergun}

Turkiye Yuksek Ihtisas Education and Training Hospital Department of Gastroenterology Kizilay Sk. 06500

Sihhiye, Ankara

Turkey

melergun@hotmail.com 